\title{
MODELING OF FORCED FLOW/THERMAL GRADIENT CHEMICAL VAPOR INFILTRATION
}

Thomas L. Starr and Arlynn W. Smith

September 1992

Report prepared by

Georgia Tech Research Institute

Georgia Institute of Technology

Atlanta, Georgia 30332

Project A-4373

under

Subcontract $19 \times-55901$

for

Oak Ridge National Laboratory

Oak Ridge, Tennessee 37831

managed by

Martin Marietta Energy Systems

for the

U.S. Department of Energy

under Contract No. DE-AC05-84R21400 
This report has been reproduced directly from the best avallable copy.

Available to DOE and DOE contractors from the Office of Scientific and Technical Information, P.O. Box 62, Oak Ridge, TN 37831; prices available from (615) 576-8401, FTS 626-8401.

Available to the public from the National Technical Information Service, U.S. Department of Commerce, 5285 Port Royal Rd.; Springfield, VA 22161.

This report was prepared as an account of work sponeored by an agency of the United States Government. Neither the United States Government nor any agency thereof, nor any of their omployees, makes any warranty, expresend or implied, or assumes any legal liability or responsibility for the accuracy, completeness, or usefulness of any information, apparatua, product, of procese dieclosed, or represents that its use would not infringe privately owned rights. Roference heroin to any specific commercial product, process, or service by trade name, trademark, manufacturer, or otherwies, does not necesearily constitute or imply its endorsement, recommendation, or favoring by the United States Government or any agency thereof. The viewe and opinions of authore expresesd herein do not nocesearily state or reflect those of the United States Government or any agency thereof. 


\section{MODELING OF FORCED FLOW/THERMAL GRADIENT \\ CHEMICAL VAPOR INFILTRATION}

Thomas I. Starr and Arlynn W. Smith

Research sponsored by the U.S. Department of Energy, Fossil Energy

Advanced Research and Technology Development Materials Program

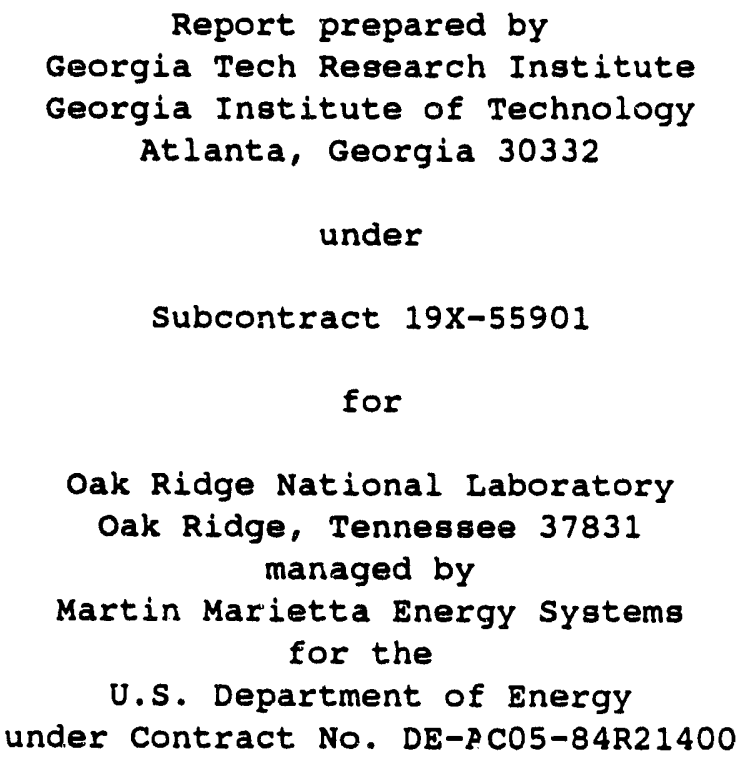


TABLE OF CONTENTS

INTRODUCTION . . . . . . . . . . . . . . . . . . . . . 1

MODEL DEVELOPMENT . . . . . . . . . . . . . . . . . . . . . . 1

SEECIFICATION OF MODEL PARAMETERS . . . . . . . . . . . . . . . . 8

SIMULATION OF DISK DENSIFICATION . . . . . . . . . . . . . . . . 17

SIMULATION OF TUBE DENSIFICATION . . . . . . . . . . . . . . . 21

SUMMARY AND CONCLUSIONS . . . . . . . . . . . . . . . . . . 27

REFERENCES . . . . . . . . . . . . . . . . . . . . . 28 


\section{LIST OF FIGURES}

Figure 1. Region of interest is divided into finite volume elements using a cylindrical coordinate system. Values of temperature, pressure and concentration are specified at the centers of these elements. . . . . . . . . . . . . . . . . . . . . . . . 2

Figure 2. Schematic diagram of preform microstructure model. Parameters are described in the text. . . . . . . . . . . . . . . . 9

Figure 3. Initially the surface area of a cloth lay-up preform is high but falls sharply as density increases. . . . . . . . . . . . . . . 11

Figure 4. Thermal conductivity of SiC/Nicalon composite is anisotropic and density dependent. . . . . . . . . . . . . . . . . . . . .

Figure 5. Gas permeability of composite varies for flow parallel and perpendicular to the cloth and decreases with increasing density. .14

Figure 6. Analytical grid for the "small" ORNL CVI reactor shown in Figure 2 includes $\mathbf{s i x}$ elements in the radial direction and eleven in the vertical. The preform area itself is divided into a $5 \times 5$

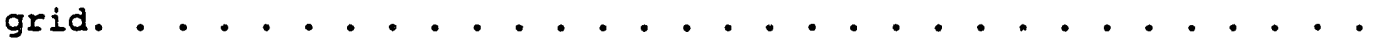

Figure 7. Model prediction for backpressure shows good match to experimental measurements except that model pressure rises too sharply near the end of the run.

Figure 8. Model predicted density matches experiment at bottom, middle and top of preform after nine hours of processing. Range of values plotted corresponds to variation in density from the center to the edge of the disk. . . . . . . . . . . . . . . . . . . .

Figure 9. Model predicted density matches experiment at bottom, middle and top of preform after 22 hours of processing. . . . . . . . . .

Figure 10. Model predicted density matches experiment at bottom, middle and top of preform after 28 hours of processing.

Figure 11. Model predicted density matches experiment at bottom, middle and top of preform at end of processing (31 hours for model, 35 hours for experiment). • . . . . . . . . . . . . . . . . . . . .

Figure 12. Schematic and finite element grid of the ORNL tube infiltration system. . . . . . . . . . . . . . . . . . . . .

Figure 13. Overall density increase is approximately linear with time but backpressure increases steeply near end of run. . . . . . . . . 
Figure 14. Density profile at intermediate times during infiltration shows progressive densification from the outside center of the tube. •. . . . . . . . . . . . . . . . . . . . . . . . .

Figure 15. The gas flow pattern changes somewhat as densification progresses . . . . . . . . . . . . . . . . . . . . . .

Figure 16. The temperature profile changes as densification progresses with increasing temperature near the inner part of the preform. 


\section{INTRODUCTION}

The forced flow/thermal gradient chemical vapor infiltration process (FCVI) has proven to be a successful technique for fabrication of ceramic matrix composites ${ }^{1}$. It is particularly attractive for thick components which cannot be fabricated using the conventional, isothermal method (ICVI).

Although it offers processing times that are at least an order of magnitude shorter than ICVI, FCVI has not been used to fabricate parts of complex geometry and is perceived by some to be unsuitable for such components. The major concern is that selection and control of the flow pattern and thermal profile fox optimum infiltration can be a difficult and costly exercise. In order to reduce this effort, we are developing a computer model for FCVI that simulates the densification process for given component geometry, reactor configuration and operating parameters. Used by a process engineer, this model can dramatically reduce the experimental effort needed to obtain uniform densification.

A one-dimensional process model, described in a previous interim report $^{2}$, has demonstrated good agreement with experimental results in predicting overall densification time and density uniformity during processing and the effect of various fiber architectures and operating parameters on these process issues. This model is fundamentally unsuitable for more complex geometries, however, and extension to two- and three-dimensions is necessary. This interim report summarizes oux progress since the previous interim report toward development of a "finite volume" model for FCVI.

MODEL DEVELOPMENT

The FCVI process involves transport and conservation of energy, momentum and mass. The physical laws governing these processes can be expressed as a system of differential equations. While these equations offer the desired simulation of the infiltration process, an analytical solution is possible only for simple geometries and boundary conditions. For the more general situation - where our interest lies - a numerical approach is necessary. One

Research sponsored by the U.S. Department of Energy, Fossil Energy AR\&TD Materials Program, DOE/FE AA 151010 , Work Breakdown Structure Element GT-1(A) 
such technique, the "finite volume" method, has proven successful for modeling a wide range of processes involving chemical reaction and heat and fluid flow ${ }^{3}$. We have used this method to model FCVI.

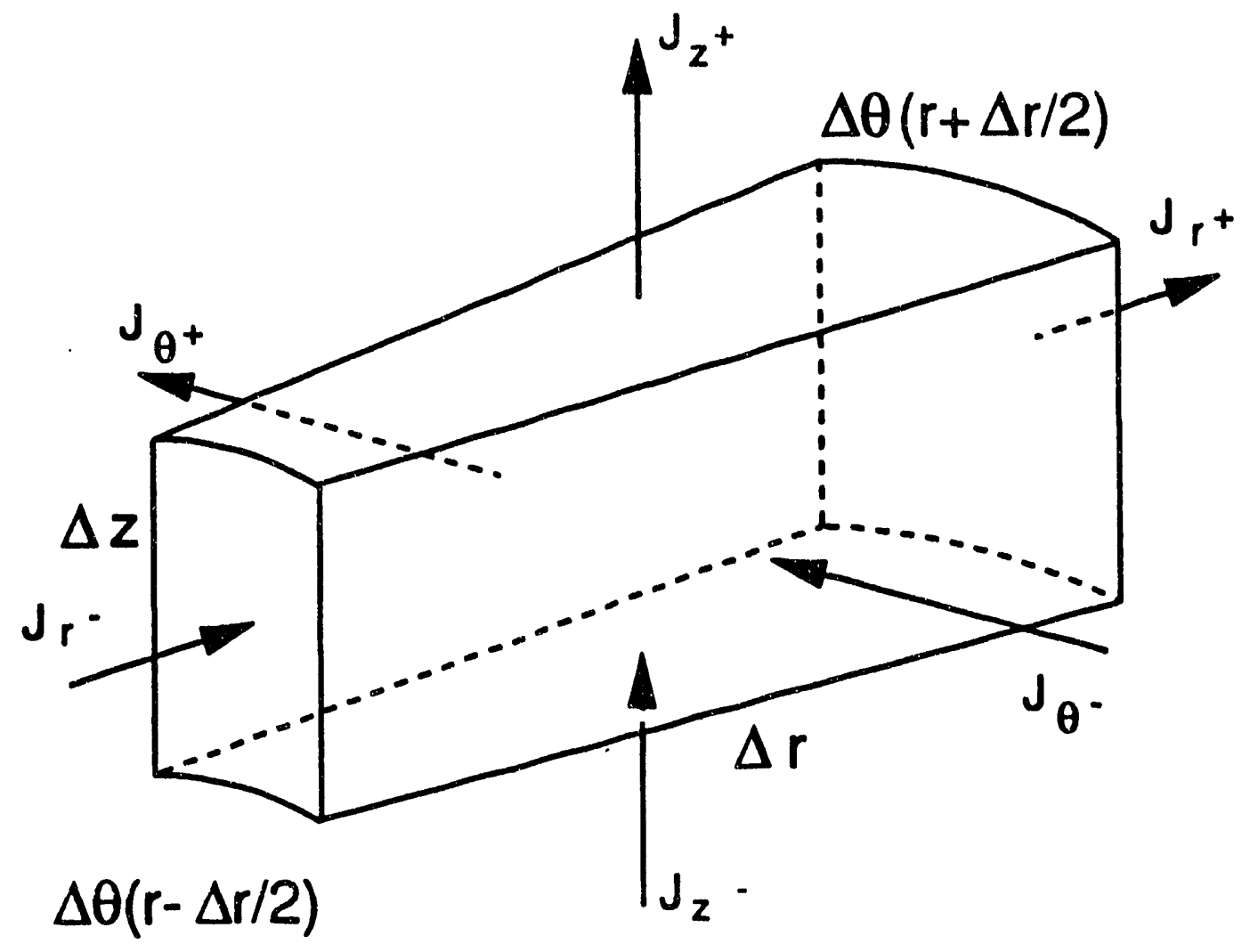

Figure 1. Region of interest is divided into finite volume elements using a cylindrical coordinate system. Values of temperature, pressure and concentration are specified at the centers of these elements.

In the finite volume method, the region of interest is divided into an orthogonal array of volume elements. Figure 1 illustrates one such volume element, in a cylindrical coordinate system. A value for a process parameter (temperature, pressure or concentration) is specified at a grid point located at the center of each volume element. This array of discrete values approximates the real, continuous variation of the parameter over the region of interest.

In the steady-state, the value of a parameter at each grid point can be 
related to its neighboring values utilizing the conservation principle. For temperature, as an example, the heat flow into and out of the volume element (flux) is required to balance any heat generation or absorption within the element (source). This relationship produces a system of linear equations, one equation for each grid point. The solution of this set of equations produces the values of the parameter at each grid point.

The flux term in the conservation equations has the general form,

$$
f l u x=u A G-D \frac{d G}{d x}
$$

where $G$ is a system parameter, such as temperature, $u$ is the flow velocity in the $x$-direction through a face of the volume element, $A$ is a constant related to the "convective" flux and $D$ is a constant related to the "diffusive flux".

The source term in the conservation equations can have many forms but it is useful to express it as an explicit linear function of the system parameter, that is,

$$
\text { source }=S_{c}+S_{p} G
$$

where $s_{c}$ and $s_{p}$ are constants. In actual practice, $s_{c}$ and $s_{p}$ can depend on the system parameter so that this convention allows inclusion of non-linear source contributions, such as a second-order reaction.

For the FCVI process the important parameters include temperature, pressure and concentration of chemical species. Flux and source terms are associated with each parameter. For temperature, flux terms include heat conduction and convection. The heat of reaction is a source term for temperature but is very small and we do not include this in our model. For pressure, the flux term consists of viscous flow as expressed by Darcy's Law. Again, the source term resulting from chemical reaction is very small and is neglected. For concentration of chemical species, flux terms include diffusion and convection. The source term, production or depletion through chemical reaction, is of central importance and is included.

In order to solve the system of equations generated by the conservation principle, boundary conditions must be specified at every grid point on the edge of the region of interest. In general, either the value of the system parameter or the value of the flux is specified. Selection of the region of 
interest is influenced, to a great extent, by the need to have well determined boundary conditions.

Mathematically, modeling of temperature, pressure and concentration are identical problems. They differ only in the values of the parameters and constants, the form of the source term and the boundary conditions.

\section{Temperature}

For the temperature problem, the diffusive flux in (1) corresponds to thermal conduction, with the constant, $D$, equal to the thermal conductivity. The region of interest for the FCVI model will include volume elements that consist of different materials and, thus, different thermal conductivities. Some of these materials, such as the graphite used to construct the preform holder, remain unchanged as infiltration proceeds. The preform, however, changes dramatically in density during the process and its thermal conductivity changes as a consequence. Furthermore, for a cloth lay-up preform, the thermal conductivity is expected to be different parallel and perpendicular to the cloth layers. Provision for density dependent, anisotropic transport properties has been included in the CVI model.

The convective flux for temperature is due to heating of the cool gas as it moves through the preform and the coefficient, $A$, is equal to the heat capacity of the gas. For hydrogen and for gas flow rates used at ORNL, the convective contribution is only about $5 \%$ of the total heat flux through the preform.

\section{Pressure}

For pressure, the diffusive flux corresponds to viscous flow through a porous medium as expressed by Darcy's Law,

$$
F=\frac{K}{\mu V_{m}} \frac{d P}{d x}
$$

where $F$ is the molar flux (moles/s/ $\mathrm{cm}^{2}$ ), $V_{\mathrm{m}}$ is the molar volume of the $g a s, \mu$ is the gas viscosity, and $k$ is the permeability. Permeability depends only on the structural properties of the porous medium while $\mu$ and $V_{m}$ depend only on the gas. Like thermal conductivity, gas permeability is expected to be density dependent and may be anisotropic for certain preform architectures. 
There is no convective flux term for pressure in our model. This assumption corresponds to the "potential flow" approximation in fluid dynamics which neglects contributions due to gas inertia and bouyancy. While not accurate for gas flow in oper reactors or ducts, this model corresponds exactly to pressure driven flow through semi-permeable bodies as is our case.

\section{Concentration}

For concentration modeling the diffusive flux term corresponds to gas phase diffusion. The effective diffusion coefficient will depend on the nature of the chemical species, the total pressure and the preform microstructure. For a porous solid the effective diffusion coefficient can be expressed,

$$
D_{\theta}=D \frac{p}{\tau}
$$

where $D$ is the ordinary or the Knudsen diffusion ccefficient for the chemical species an the gas mixture, $p$ is the fraction porosity in the porous body and $\tau$ is a "tortuosity" factor. For FCVI, normally run near ambient pressure, ordinary, or Fickian, diffusion is appropriate and the value of $D$ can be obtained from chemical engineering tables or from kinetic theory formulas. The porosity is easily calculated from the density, but the tortuosity depends on microstructure in a complex way. For anisotrcpic matesials, the tortuosity may be different in different directions, giving an anisotropic effective diffusion coefficient.

The convective flux term corresponds to movement of the reactive species in the overall gas flow. For concentration expressed as mole fraction and flow velocity as molar flux, the convection coefficient, $A$, in (1) is unity. For typical FCVI flow rates the convective flux through a volume element is much larger than the diffusive flux.

The source term for concentration corresponds to the reaction rate of the chemical species within the volume element. For surface deposition reactions the volumetric reaction rate, $R_{v}$, can be expressed as,

$$
R_{v}=R_{s} S_{v}
$$

where $R_{S}$ is the reaction rate per unit of solid surface area and $S_{V}$ is the 
surface area per unit volume within the porous material. $R_{s}$ can be determined from chemical vapor deposition (CVD) experiments on flat substrates, with proper allowance for mass transport effects. $S_{v}$ depends on the microstructure of the porous composite and varies with initial fiber size and geometry and volume fraction in the preform, and with the composite density as this increases during infiltration. Obviously, $s_{v}$ must go to zero as the density increases to near $100 \%$.

\section{Densification}

The above formulation of the finite volume model results in a steadystate solution, giving the temperature, pressure and concentration at one moment in time. As part of this solution we also obtain the molar deposition rate for each volume element. Using the stoichiometry of the deposition reaction and the molecular weight, $M$, and density, $\sigma$, of the product we can convert this to a densificaton rate,

$$
R_{d}=\frac{n R_{v} M}{\sigma}
$$

where $\mathrm{n}$ is the number of moles of product for each mole of reactant and $\mathrm{R}_{\mathrm{d}}$ is the increase in the volume fraction of solid per unit time. For a given increment of time, $\Delta t$, the new density can be calculated by linear extrapolation,

$$
d(t+\Delta t)=d(t)+R_{d}(t) \Delta t
$$

This explicit formulation for densification is reasonably accurate for small time increments or when the densification rate, $R_{d}$, is reasonably constant with time. However, at near full density, where the surface area and, thus, the deposition rate, goes to zero, this method can produce a relative density greater than $100 \%$. In order to avoid this problem, we employ an implicit formulation for densification,

$$
d(t+\Delta t)=d(t)+R_{d}(t+\Delta t) \Delta t
$$

where $R_{d}$ is calculated using the steady-state temperature, pressure and concentration values but with the surface area function, $s_{v}$, for the new density. This formulation requires an iterative solution method but gives a 
smooth approach to full density with even relatively coarse time steps.

With new densities for each volume element, new values of the transport coefficients are calculated and new steady-state values for temperature, pressure and concentration are obtained. With multiple time increments we get a. series of "snapshots" of the infiltration process. This iteration process can be continued for an arbitrary period but is usually terminated at some set value of composite density or inlet pressure.

\section{Computer program}

The finite volume model outlined above has been incorporated into a FORTRAN computer program. Input to this program includes the geometry of the CVI reactor, boundary conditions for temperature, pressure and concentration, and a series of time increments. Four types of volume element are used to specify a FCVI process system. A free space element is used for the gas inlet up to the preform. A graphite element is used for the preform holder and gas injector. A porous araphite element is used for the cover plate. A preform element is used for the preform region. Iransport properties for each of these types of elements must be specified.

Built into the program are routines for estimating the transport coefficients (thermal conductivity, gas permeability, etc.) and reaction kinetics factors for the reactants involved in the particular CVI system. This part of the model is continually evolving as better understanding is gained.

The program uses an iterative, line-by-line method for solving the gystems of linear equations. Solutions for temperature, pressure and concentration are obtained separately but this procedure is iterated until the solutions are consistent. Thus, temperature dependence of the gas flow and flow dependence of the temperature profile are properly calculated. For: each time step values of temperature, pressure, concentration, density and the flow vectors for each grid point are written to a file. These results can be analyzed and displayed using stand-alone data analysis and graphics display software packages. 
The CVI model will always produce a simulation of the CVI process. Whether this simulation matches the actual, experimental process depends critically on accurate specification of transport properties and reaction kinetics, and on proper selection of boundary conditions. Ongoing experimental efforts at Georgia Tech and at ORNL are directed toward better understanding of these factors for SiC/Nicalon composites.

\section{Microstructure Model}

A microstructure model is a key requirement for successful CVI simulation. This model should (1) predict the physical microstructure of the partially infiltrated composite as a function of density, (2) allow estimation of transport properties, such as gas permeability and thermal conducts..ily, (3) be based on fundamental principles and measurable geometric quantities, and (4) be trangferable to various preform architectures.

Our microstructure model is based on combining individually the principal microstructural features of the preform. For a cloth lay-up preform, three features are apparent - the densely packed fiber tows, rectangular cioles that run perpendicular to the cloth layers and channels between cloth layers. These are illustrated schematically in Figure 2 . specification of the volume fraction of each feature and its characteristic dimension constitutes a complete microstructure model for the preform.

The "channel" feature is specified by one parameter, $z_{c}$ ' the distance between cloth layers. This value can be estimated from micrographs of the preform cross-section or from physical measurements of the cloth thickness and the average layer spacing, $z$, in the preform. The channel volume fraction is equal to the ratio of the channel width to the average layer spacing.

The "hole" feature is specified by one parameter, $x_{h}$, the width of the rectangular hole. This value is nieasured microscopically. The hole volume fraction is calculated from this value, the layer spacing and the distance between holes, $x$, which also is measured by microscopic examination.

The thickness of the "tow" feature is equal to the difference between the layer spacing and the channel width. Its volume fraction is the remainder 


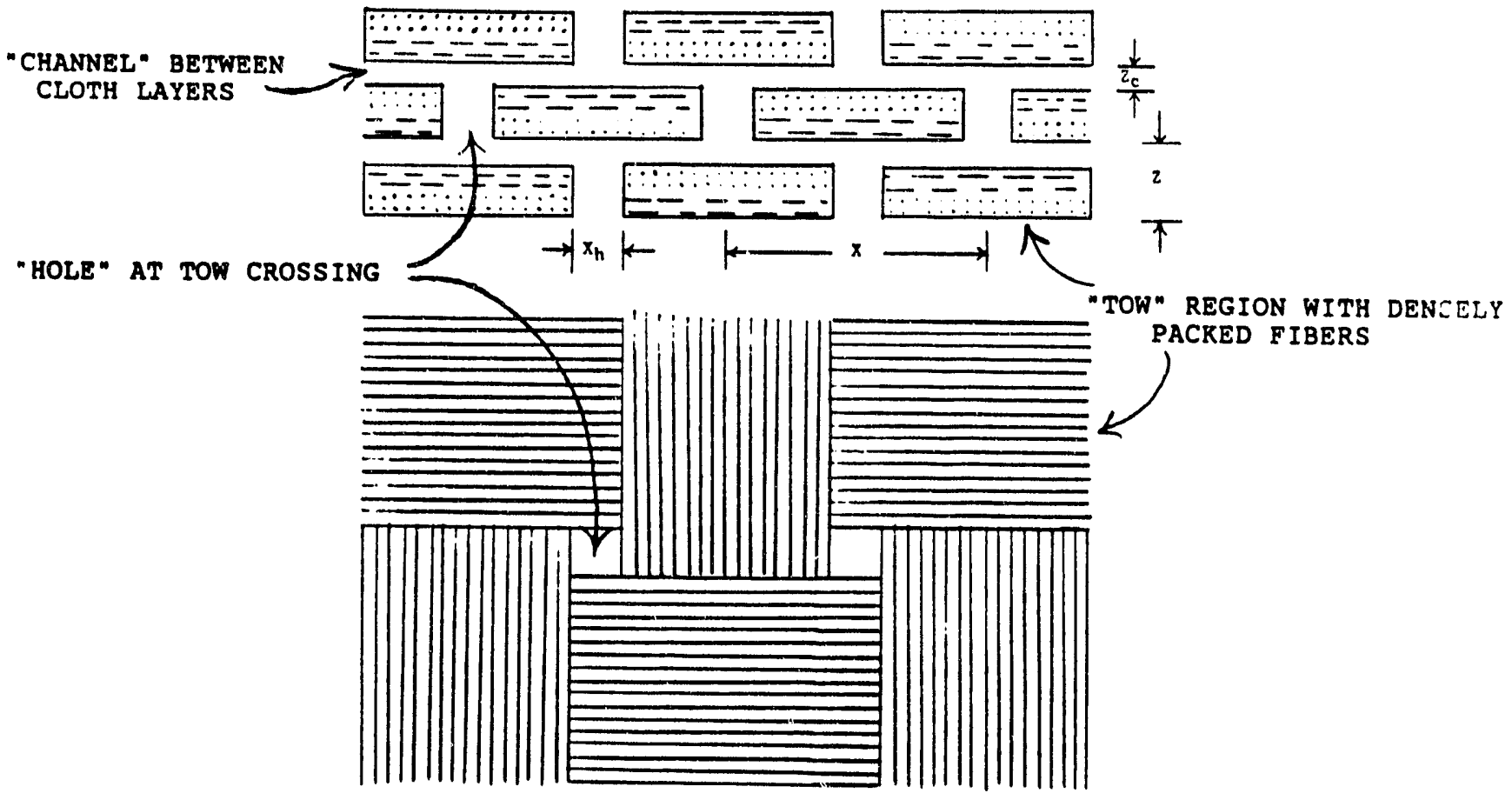

Pigure 2. Schematic diagram of preform microstructure model. Parameters are described in the text.

after accounting for the hole and channel fractions. Whereas the hole and channel features are empty volume, the tow consists of densely packed, parallel fibers of specified diameter. The volume fraction fiber in the tow regions is equal to the volume fraction fiber in the preform divided by the volume fraction tow region.

This microstructure model is completely specified by seven parameters: fiber diameter; volume fraction fiber in the preform, hole width, channel width, layer spacing, volume of closed porosity in tow at "full" densification, and distance between holes. Each of these corresponds to a real physical quantity which can be measured directly. 


\section{Surface Area}

During CVI the composite is formed by deposicion of the matrix material onto the internal surfaces of the preform. Assuming that the deposition rate is uniform throughout a small volume element, the increase in density is proportional to the surface area. This is calculated from the surface area per unit volume for each feature multiplied by its volume fraction in the composite. For the hole and channel volumes, the surface area function is calculated easily from their dimensions. For the tow region, the surface area per unit volume, $s_{t}$, is given by:

$$
s_{t}=\frac{4}{d}\left(\frac{f_{0}}{f_{\infty}-f_{0}}\right)^{1 / 2}\left\langle f\left(f_{-\infty}-f\right)\right)^{1 / 2}
$$

where $f$ is the current volume fraction solid (matrix and fiber) in the tow, $f_{0}$ is the initial volume fraction fiber, $f_{\infty}$ is the solid volume fraction at "full" density (allowing for closed porosity), and d is the fiber diameter.

We have determined microstructure model parameters for a typical ORNL CVI preform of 52 layers, $1.25 \mathrm{~cm}$ thick, and with 408 fibers $15.7 \mu \mathrm{m}$ in diameter. The hole width and spacing are .035 and $.150 \mathrm{~cm}$, respectively. The channel width is estirated to be $60 \mathrm{\mu m}$. The calculated volume fractions for each feature are 24.88 channel, 4.18 hole and 71.18 tow.

The surface area function for this preform is shown in Figure 3 . Initially the surface area is high but falls sharply as density increases. Near $70 \%$ dense the tow regions are fully dense and the surface area is small, corresponding to the surface of holes and channels. Densification will continue at a slow rate until the channel regions close at roughly $96 \%$ density. This is in agreement with experimental results which give densities between 85 and 958 over a wide range of infiltration conditions ${ }^{4}$. The ultimate density is determined more by the preform architecture than by the infiltration conditions.

\section{Reaction Kinetics}

For CVI of silicon carbide matrix composites using methyltrichlorosilane (MTS) the overall reaction is,

$$
\mathrm{H}_{3} \mathrm{CSiCl}_{3}+\mathrm{nH}_{2}-\mathrm{SiC}+3 \mathrm{HCl}+\mathrm{nH}_{2}
$$




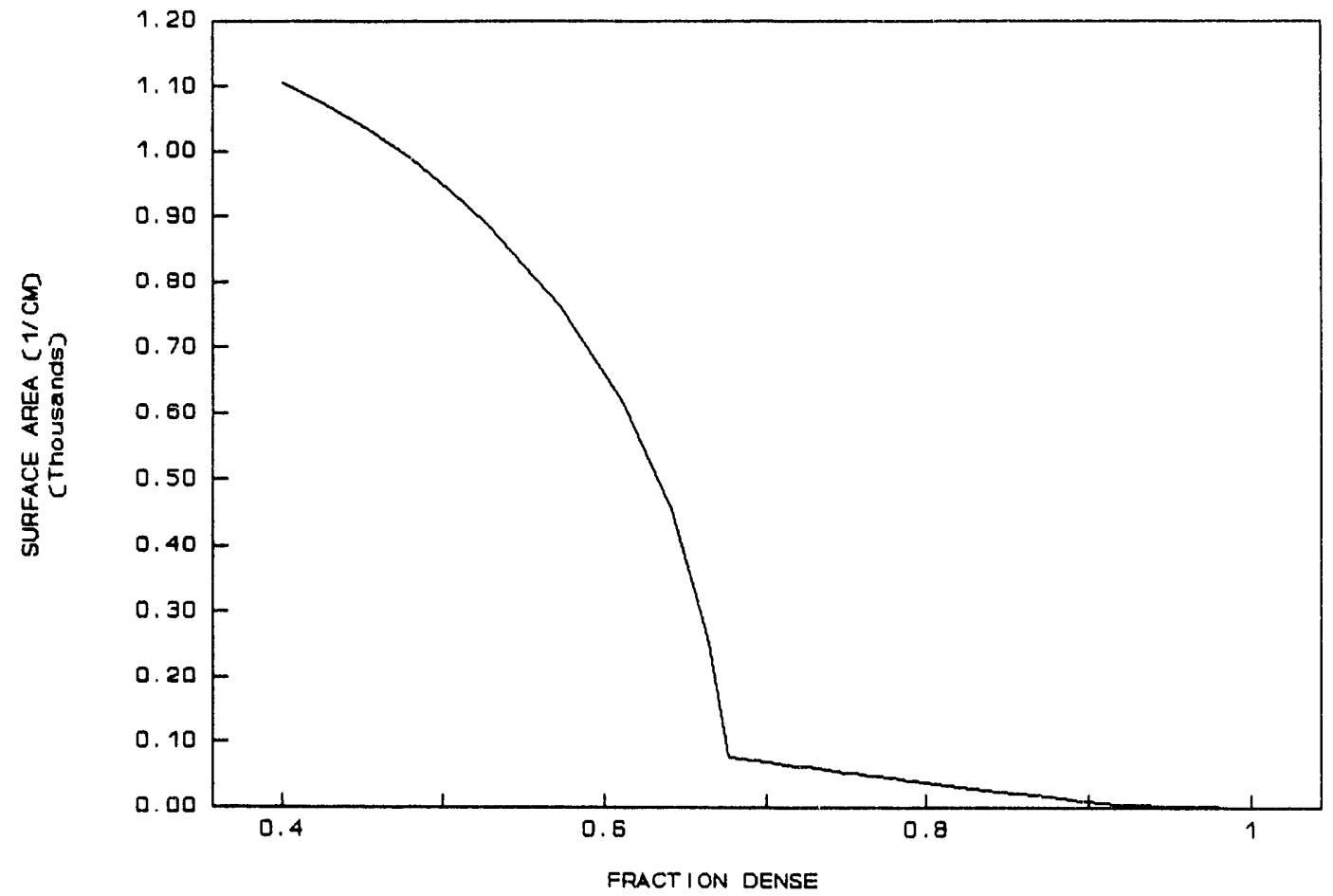

Figure 3. Initially the surface area of a cloth lay-up preform is high but falls sharply as density increases.

showing one mole of silicon carbide for each mole of MTS reacted. In reality, the -eaction is more complex with a number of intermediate reactions and reaction products. In spite of this complexity, experimental measurements of deposition rate onto fibers by Brennfleck, et al. ${ }^{5}$, fit a relatively simple rate equation of the form,

$$
R_{s}=A e^{-E / R T} C
$$

where $C$ is the mole fraction MTS, $R$ is the gas constant, $T$ is the temperature, $E$ is the activation energy and $A$ is the kinetic rate constant. For $R_{S}$ in moles $/ \mathrm{s} / \mathrm{cm}^{2}, A=.0022$ and $E=120 \mathrm{~kJ} / \mathrm{mole}$. This rate law has given reasonably good fit to experimental densification times using a 1-D CVI model ${ }^{6}$. More recently, experiments at ORNL over a range of flow rates and gas 
compositions indicate a more complex deposition rate relationship that includes a strong inhibition effect due to the accumulation of $\mathrm{HCl}$, a byproduct of the reaction ${ }^{7}$. This yields the rate expression,

$$
R_{1}=\frac{k_{x} P_{x}}{1+K_{p} P_{p}}
$$

where $R_{l}$ is the linear deposition rate, $P_{r}$ and $P_{p}$ are partial pressures of reactant (MTS) and product ( $\mathrm{HCl}$ ), $\mathrm{k}_{\mathfrak{r}}$ and $\mathrm{k}_{\mathrm{p}}$ are rate constants given by Arrhenius expressions,

$$
\begin{aligned}
& K_{I}=A_{x} e^{-B_{x} / R T} \\
& K_{p}=A_{p} e^{-B_{p} / R T}
\end{aligned}
$$

where $A_{r}, A_{p}, E_{r}$ and $E_{p}$ are constants determined from CVD experiments. For conditions where $K_{p} P_{p} \ll 1, i . e$. little depletion of the reactant gas, the rate law is still nearly first-order in the reactant partial pressure. However, for $k_{p} P_{p} \gg 1, i . e$. significant depletion, the rate is proportional to the ratio of the reactant and product partial pressures.

For low values of depletion, i.e. little HCl produced, the ORNL rate is substantially higher than the Brennfleck rate. However, as the percent depletion increases, the rate can be lower or higher depending on the percent depletion and the temperature.

Heat flow

In order to calculate the temperature profile, thermal conductivities must be assigned to each of the four types of volume element. For the graphite and porous graphite elements we use $0.15 \mathrm{~W} / \mathrm{cm} / \mathrm{K}$ based on our measurements of "C grade" graphite.

For SiC/Nicalon composites, measured thermal conductivities have been reported over a range of densities both parallel and perpendicular to the cloth layers ${ }^{8}$. We fit these to equations of the form,

$$
\frac{1}{k}=\frac{f}{k_{1}}+\frac{(1-f)}{k_{2}}
$$

where $k$ is the thermal conductivity, and $k_{1}$ and $k_{2}$ are derived by fitting the experimental data. Separate, density-dependent thermal conductivities are derived for heat flow parallel and perpendicular to the cloth layers and used 


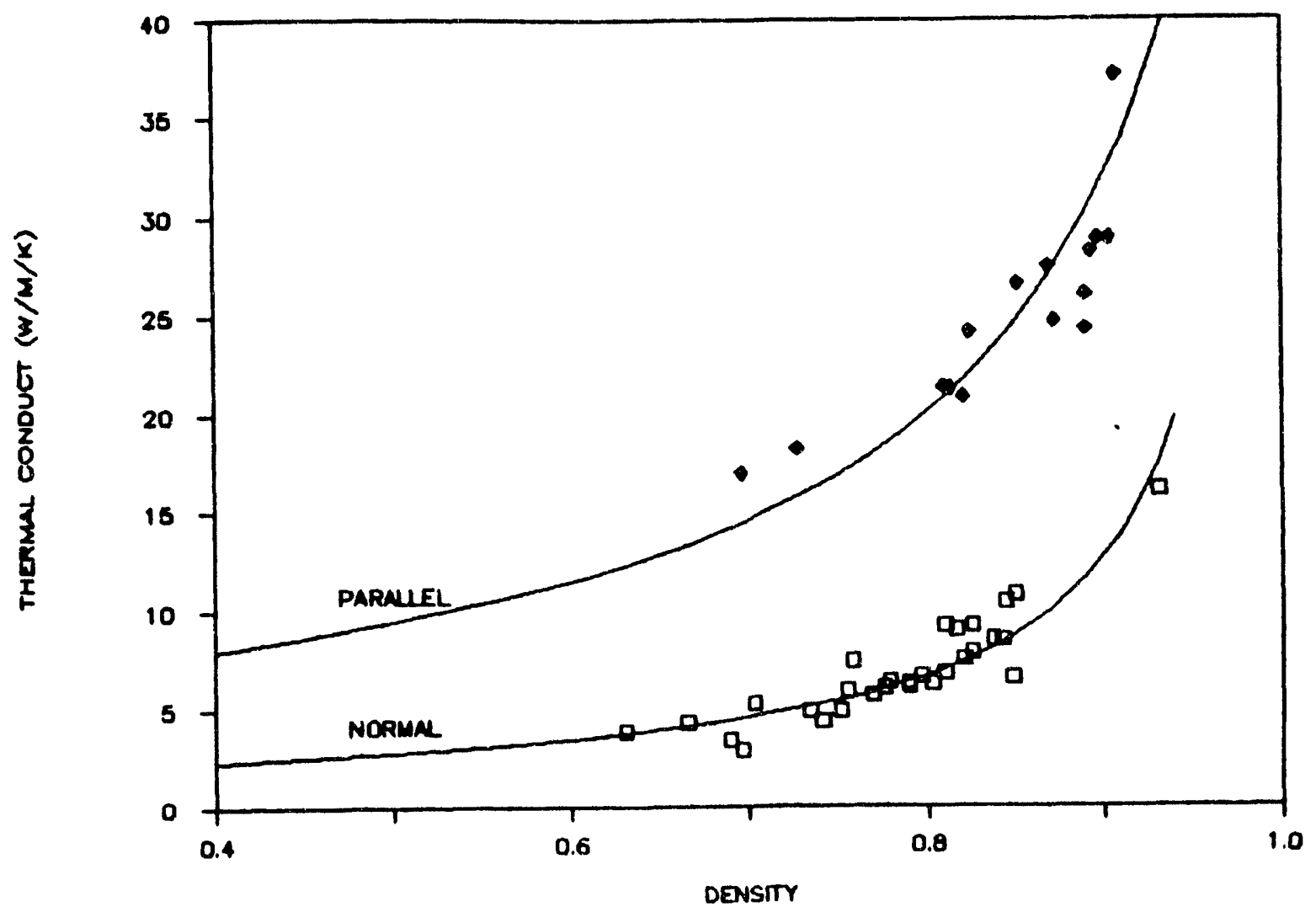

Figure 4. Thermal conductivity of Sic/Nicalon composite is anisotropic and density dependent.

for preform elements (Figure 4).

For the free space elements, the thermal conductivity is set arbitrarily to a low value of $0.005 \mathrm{w} / \mathrm{cm} / \mathrm{K}$.

To complete the thermal model we must also specify the heat capacity of the gas, $c_{p}$. We use the temperature dependent heat capacity of hydrogen ${ }^{9}$,

$$
C_{D}=27.7+0.0034 T
$$

as a reasonabie approximation for $c_{p}$ in $\mathrm{J} / \mathrm{mole} / \mathrm{K}$.

$$
\text { Gas flow }
$$

In order to calculate the pressure profile and gas flow pattern we must specify gas permeabilities for each type of element. For the two graphite 
elements and the free space element this is eas; zero for the graphite and "very large" for the free space. We arbitrarily set the "very large" as 100 Darcies $\left(100 \times 10^{-8} \mathrm{~cm}^{2}\right)$, an order of magnitude higher than the highest preform permeability.

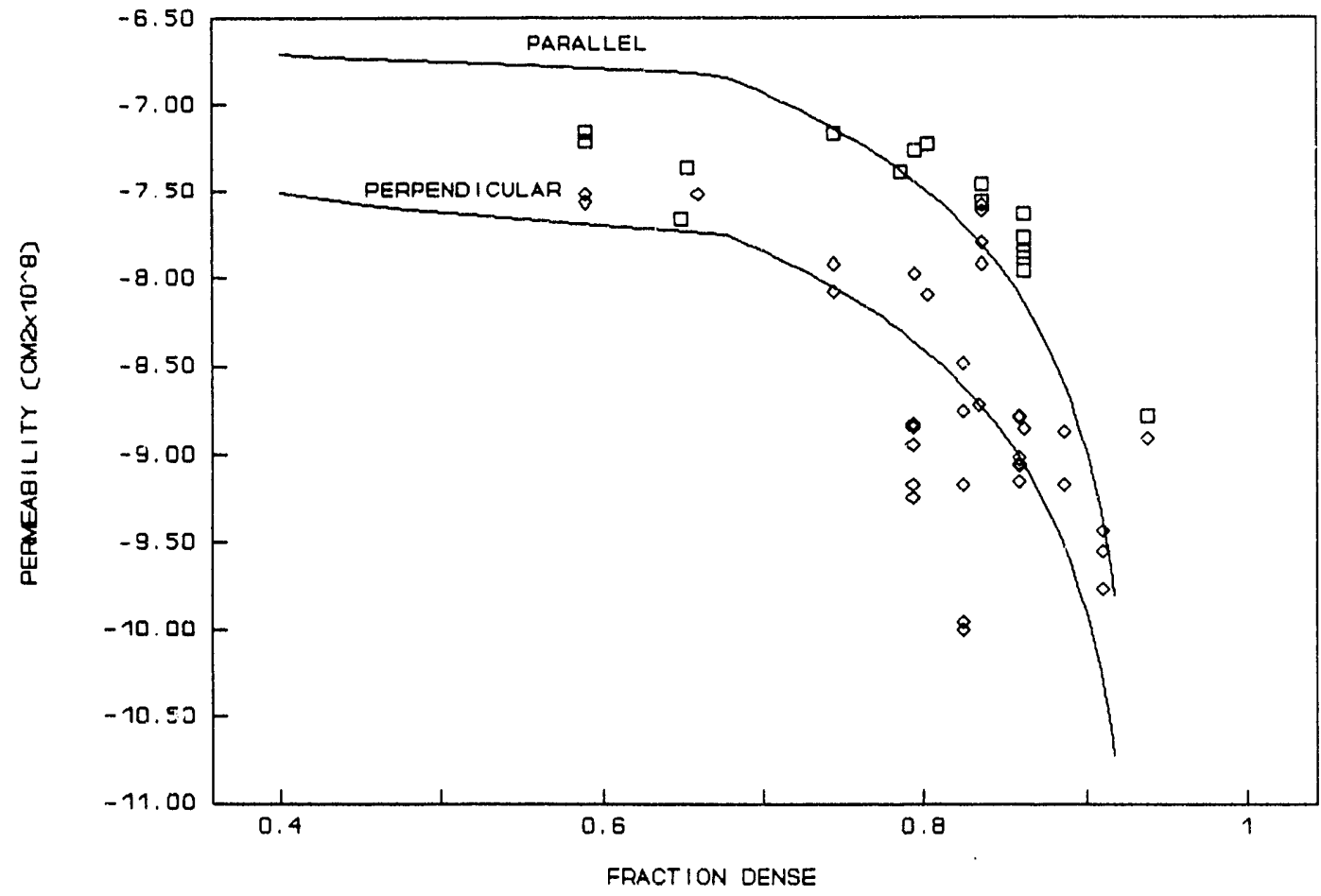

Figure 5. Gas permeability of composite varies for flow parallel and perpendicular to the cloth and decreases with increasing density.

For the preform element the gas permeability will depend on density and the specific pore microstructure as densification proceeds. We have made an number of permeability measurements using small cubes cut from partially infiltrated Sic/Nicalon cloth lay-up composites. Permeability values show the expected trends - deçreasing with increasing density and greater in the direction parallel to the cloth layers. These data are plotted in Figure 5 . The curve in this figure derives from the cloth lay-up microstructure model described above. Parallel to the cloth, most of the flow travels through the channels between layers. Perpendicular to the cloth, most of the flow travels 
a tortuous path through the holes and along channels.

In addition to the permeability, we must specify the gas viscosity in order to calculate the inlet pressure. We estimate this using the temperature dependent viscosity of hydrogen,

$$
\mu=86 \times 10^{-6}\left(\frac{T}{T_{0}}\right)^{k}
$$

where $\mu$ is the viscosity in poise and $T_{0}=273 \mathrm{~K}$.

\section{Reactant transport}

The primary mode of reactant transport is by convection in the overall gas flow. Diffusion between volume elements may be significant in regions where the magnitude of the flow is small. For the two graphite elements the effective diffusion coefficient is zero. For the free space element the diffusion coefficient is taken as the binary diffusion coefficient of methane in hydrogen, $0.625 \mathrm{~cm}^{2} / \mathrm{s}$ at $273 \mathrm{k}^{10}$. The effective diffusion coefficient for the preform element is calculated from (4) with a tortuosity factor of 2.0 .

Analytical Grid

Since the CVI reactors at ORNL have cylindrical symmetry, a 2-D model in cylindrical coordinates is appropriate for simulation of the infiltration process. An analytical grid for the "small" ORNL CVI reactor is shown in Figure 6. This grid includes six elements in the radial direction and eleven in the vertical. The preform area itself is divided into a $5 \times 5$ grid. The additional volume elements represent parts of the preform holder and gas injector. The physical boundaries between the preform and holder coincide with boundaries between volume elements. The finite volume method has been developed to properly handle such discontinuities where the transport properties can vary by orders of magnitude. This allows use of a relatively coarse grid.

\section{Boundary conditions}

Temperature, pressure and concentration boundary conditions must be specified along each boundary of the model. For temperature the top and 


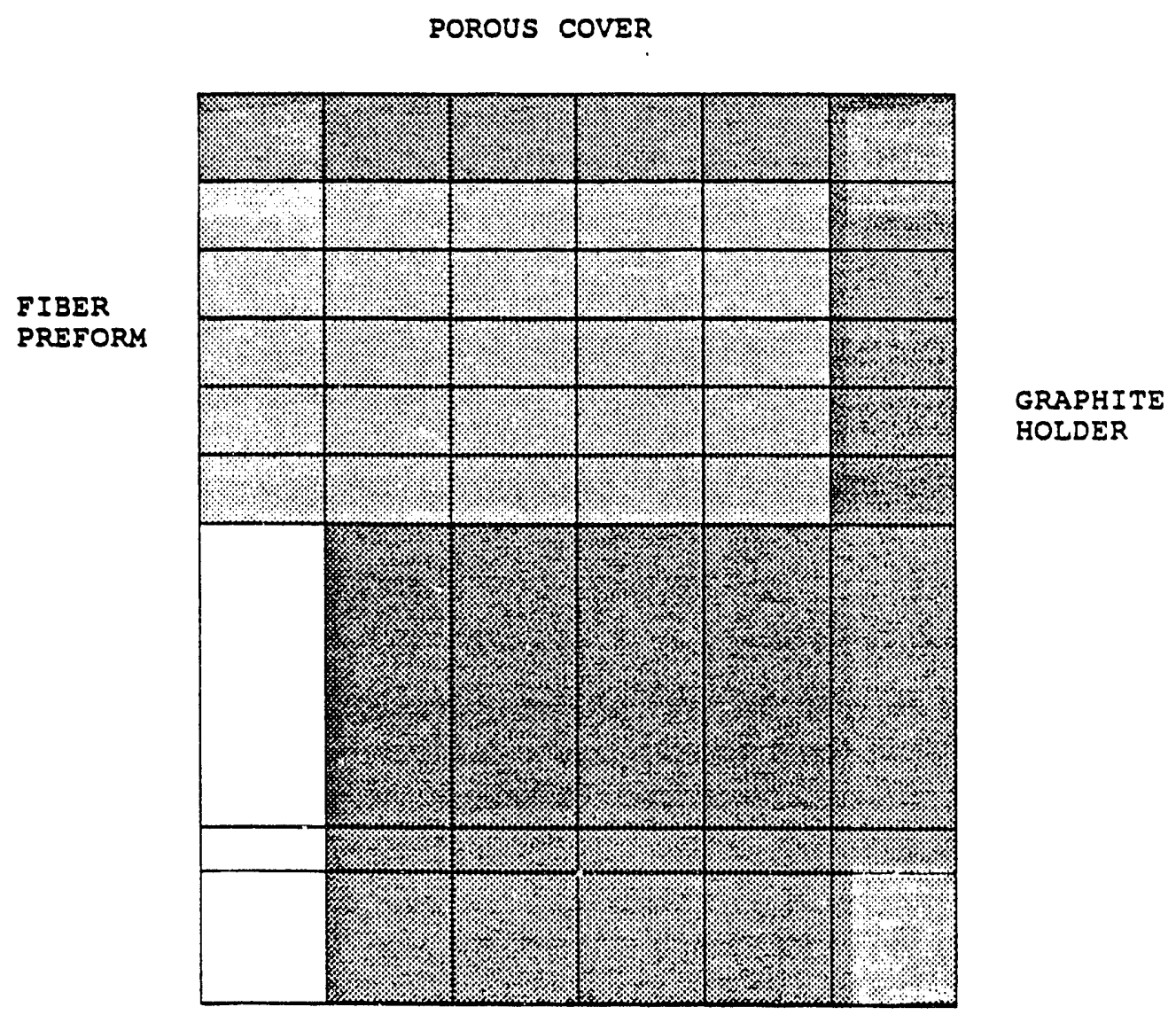

GAS INLET

Figure 6. Analytical grid for the "small" ORNL CVI reactor is shown in Figure 2. This grid includes six elements in the radial direction and eleven in the vertical. The preform area itself is divided into a $5 \times 5$ grid.

bottom boundary conditions are well determined. The reactor hardware is designed to maintain constant temperatures at the gas injector and at the upper surface of the lid. The thermal boundary condition at the radius is not so well defined due to the complexity of the furnace and reactor configuration. For now, we specify this as an adiabatic wall, $i$. e. no net heat flux through this boundary. This is in rough agreement with embedded thermocouple measurements which show only a small temperature gradient in the 
radial direction ${ }^{11}$.

The pressure boundary conditions are well defined. The top of the lid is set at constant ambient pressure of $100 \mathrm{KPa}$. All other boundaries are set as "adiabatic" walls (no flow) except for the inlet element. The inflow here is set to match the experimental gas flow.

The concentration boundary conditions also are well defined. The inflow boundary is set at the mole fraction corresponding to $\mathrm{H}_{2}$ :MTS composition. All other boundaries are set as "adiabatic" walls, i.e. no diffusion through these boundaries.

\section{SIMULATION OF DISK DENSIFICATION}

The most demanding test of a CVI model is comparison of the predicted and experimental densities at specific points in the prefcrm at a series of times prior to full densification. A set of experimental data suitable for this comparison involves four CVI runs at ORNL ${ }^{12}$. One run was continued until full densification. The other three runs, using identical temperatures and gas flow rates, were interrupted at intermediate times. Density profiles for each resulting composite were determined by slicing the disks into regular pieces and then weighing and meastring these.

We model this series of runs using a $6 \times 15$ analytical grid as shown in Figure 6. Boundary conditions for temperature, flow rate and reagent concentration are set to match experimental conditions used. Model results for back-pressure (Figure 7) are in good agreement with experiment although the model value rises a little more rapidly than experiment at the very end of the run. More importantly, local densities at intermediate times (Figure 8 through Figure 11) also show good agreement with corresponding experimental results.

This good agreement with experiment is based on a particular microstructure model, as described previously. While the parameter values in this model are not arbitrary their correspondence to physical microstructure features still must be demonstrated. This is an important step toward applying the model to CVI of larger, more complex shapes and different fiber architectures. 


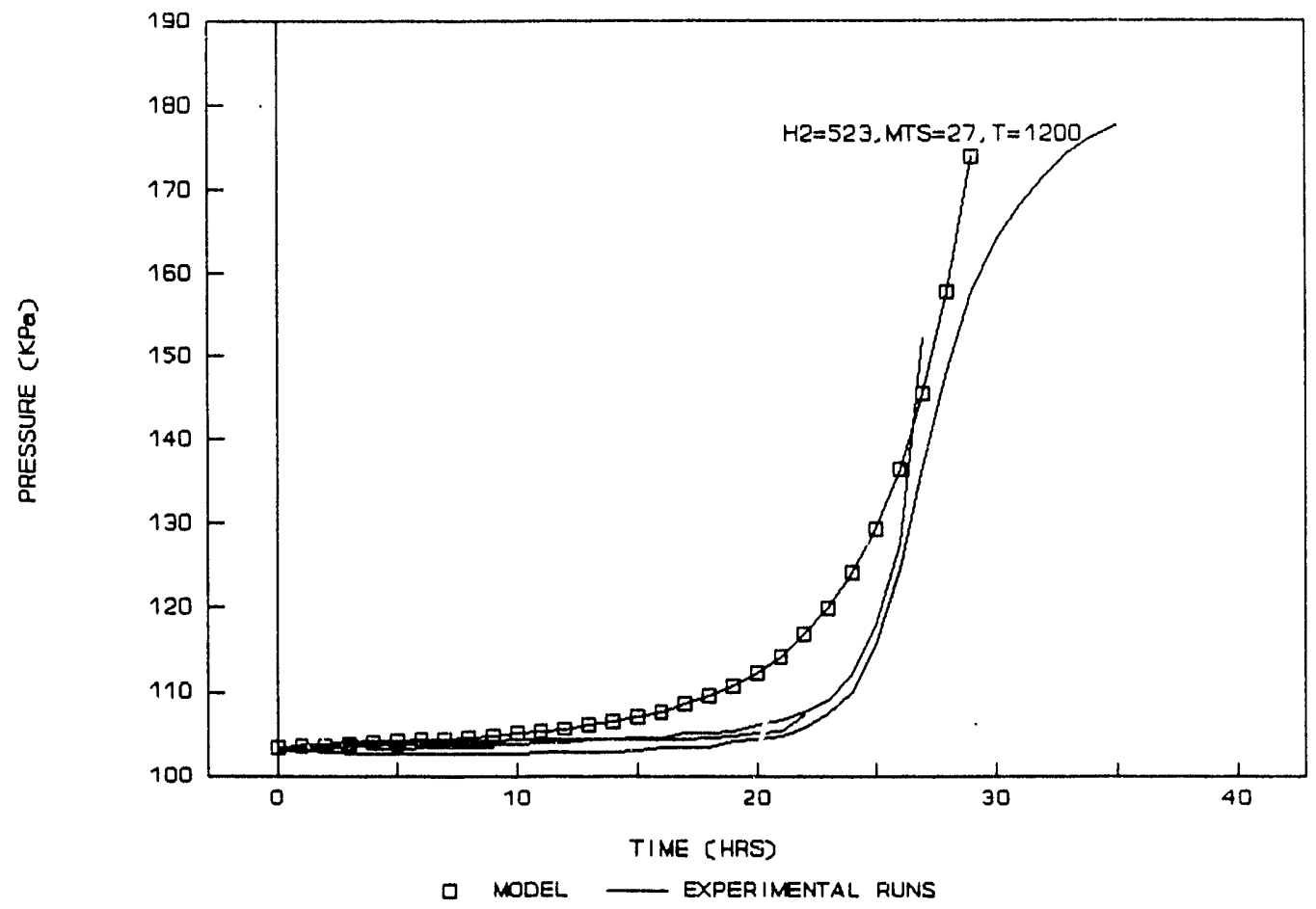

Figure 7. Model prediction for backpressure shows good match to experimental measurements except that model pressure rises too sharply near the end of the run. 


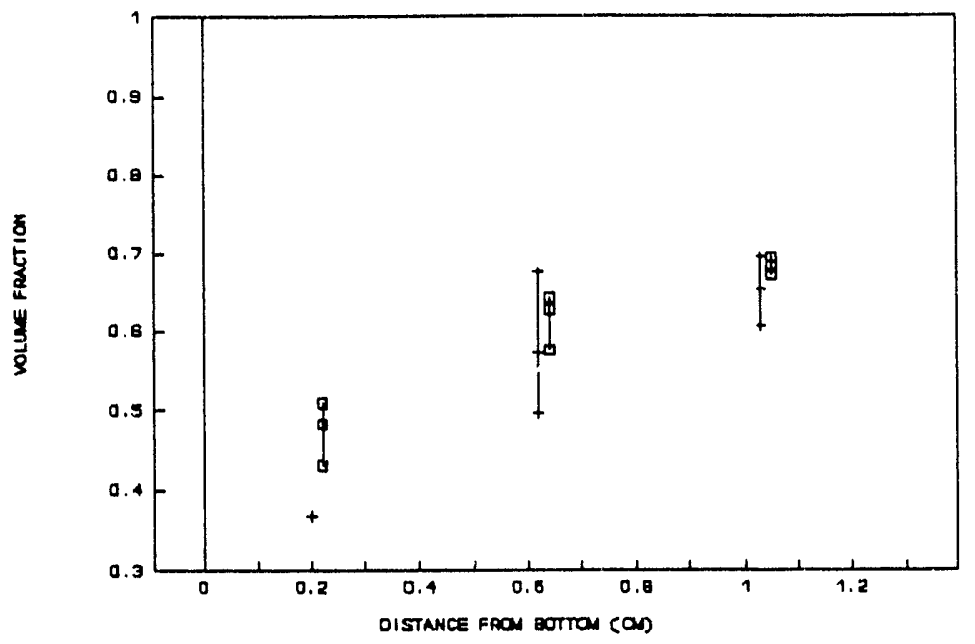

D noon + Expegiliant

Figure 8. Model predicted density matches experiment at bottom, middle and top of preform after nine hours of processing. Range of values plotted corresponds to variation in density from the center to the edge of the disk.

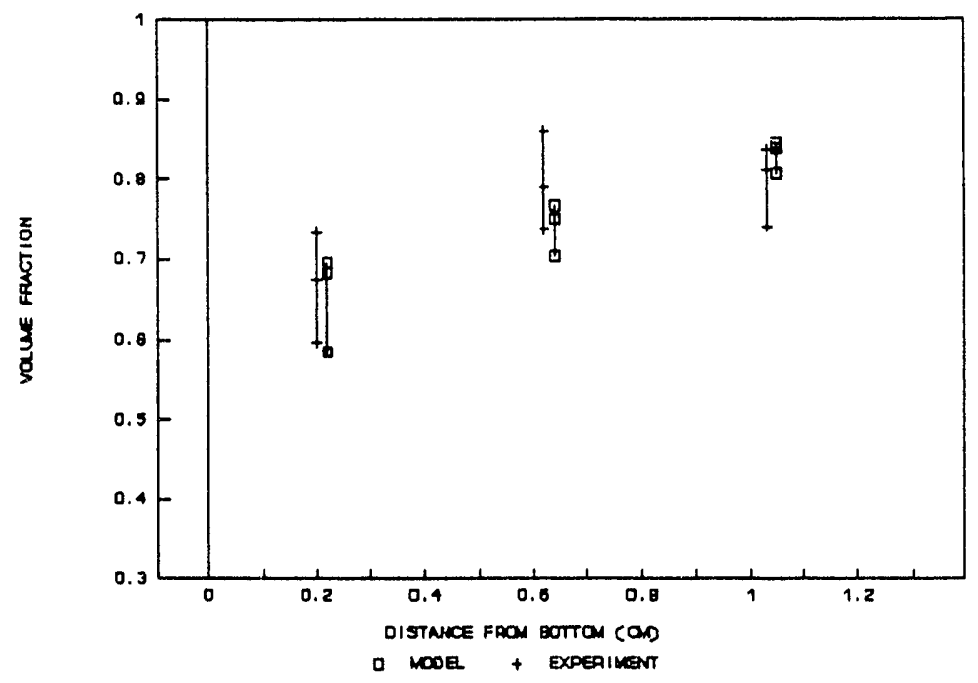

Figure 9. Model predicted density matches experiment at bottom, middle and top of preform after 22 hours of processing. 


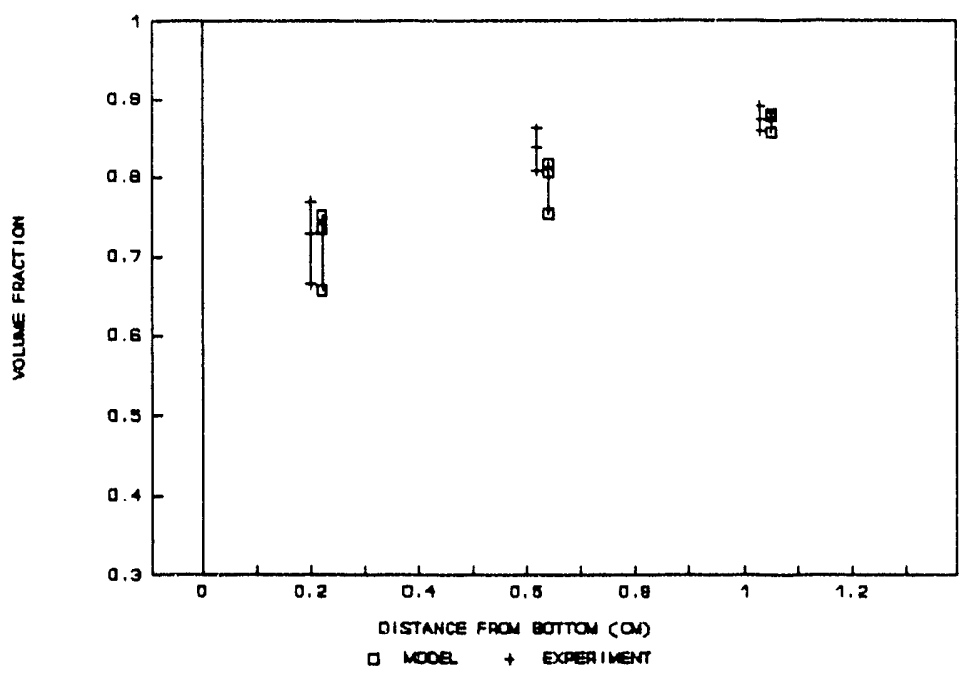

Figure 10. Model predicted density matches experiment at bottom, middle and top of preform after 28 hours of processing.

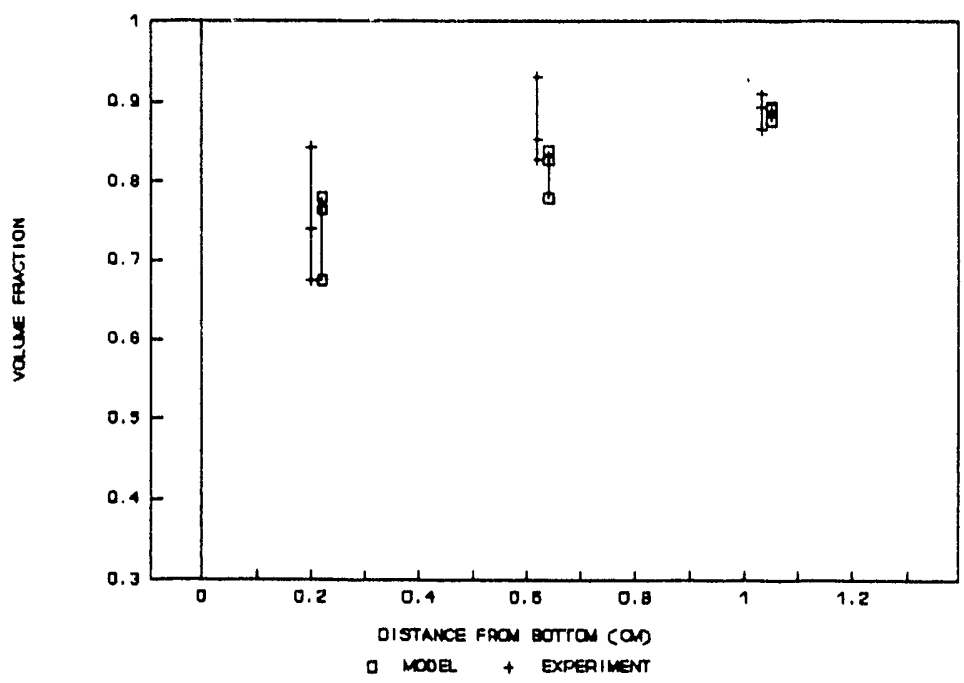

Fiçure 11. Model predicted density matches experiment at bottom, middle and top of preform at end of processing (31 hours for model, 35 hours for experiment). 
This model will be used to assist process optimization for CVI densification of filament-wound tubes at Oak Ridge National Laboratory. Initial efforts to model this particular configuration are discussed below.

Preform transport parameters, i.e. thermal conductivity, gas permeability, surface area, are very dependent on the specific fiber architecture. A filament-wound preform will have different transport properties than a cloth-wrapped preform, for example. For this initial modeling effort we will use the transport parameters previously derived for a cloth lay-up preform. Figure 12 shows a schematic of a tube shape and infiltration system for densifying the preform. The preform, $0.7 \mathrm{~cm} \mathrm{thick,} \mathrm{is}$ formed onto a hollow, porous mandrel and placed inside a furnace. Gas flows through a water-cooled tube to the center of the preform where it is directed radially toward the preform. The mandrel has channels to allow the gas to flow axially inside the preform. After passing through the preform the gas exits the reactor. Figure 12 also shows a 20 x 20 numerical grid used to model the infiltration process. Of the 400 volume elements only 105 represent the preform itself. The remaining elements represent parts of the furnace and fixtures.

Figure 13 shows the fractional density and backpressure as a function of process time for run conditions of $50^{\circ} \mathrm{C}$ water temperature, $1200^{\circ} \mathrm{C}$ furnace temperature, $750 \mathrm{sccm}$ of a 9:1 $\mathrm{H}_{2}$ :Mrs gas mixture. The increase in density is roughly linear with time, however, the backpressure increased rapidly near the end of the run. The preform density profile at intermediate times during the infiltration (Figure 14) shows progressive densification from the outside, center of the tube with a region of relatively low density along the inner diameter of the tube at the end of the run. The gas flow pattern changes somewhat as densification progresses (Figure 15) as does the temperature profile (Figure 16).

Adjustment of transport properties to better match those of the filament-wound preform and experimental temperature measurements to better set the thermal boundary conditions will allow direct comparison of model results to experimental densification behavior. With this, the model will be used as an aid to identifying optimum process parameters. 

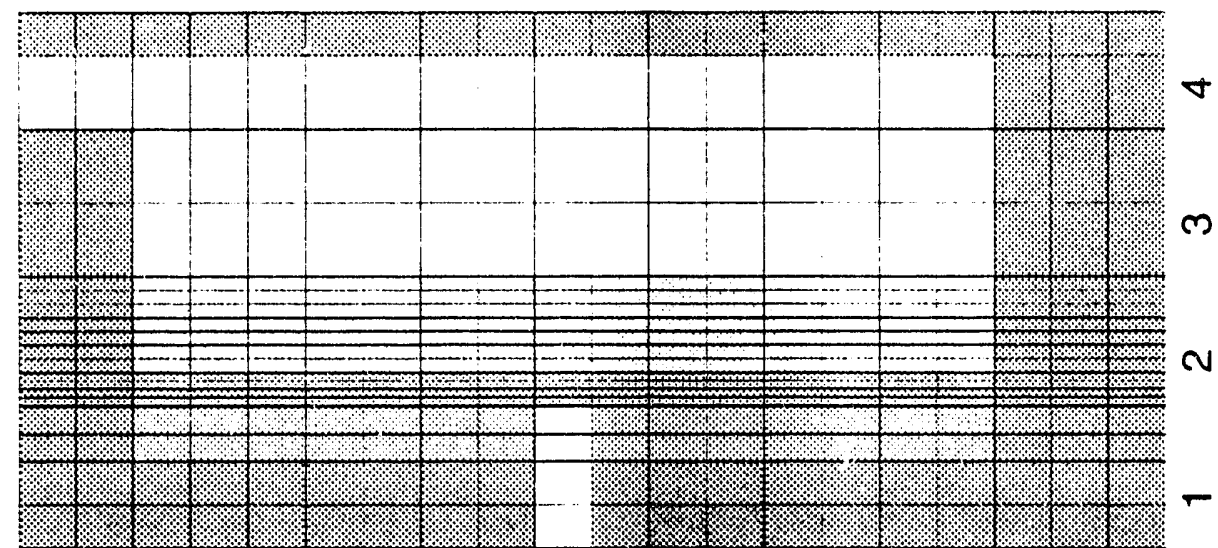

व岑

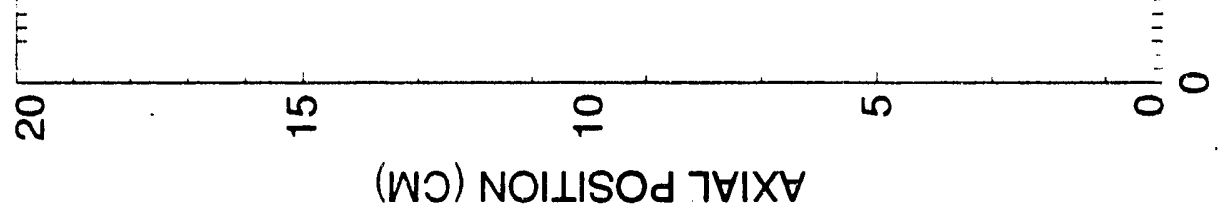

定立密

$\stackrel{\Xi}{\ddagger}$

茨

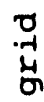

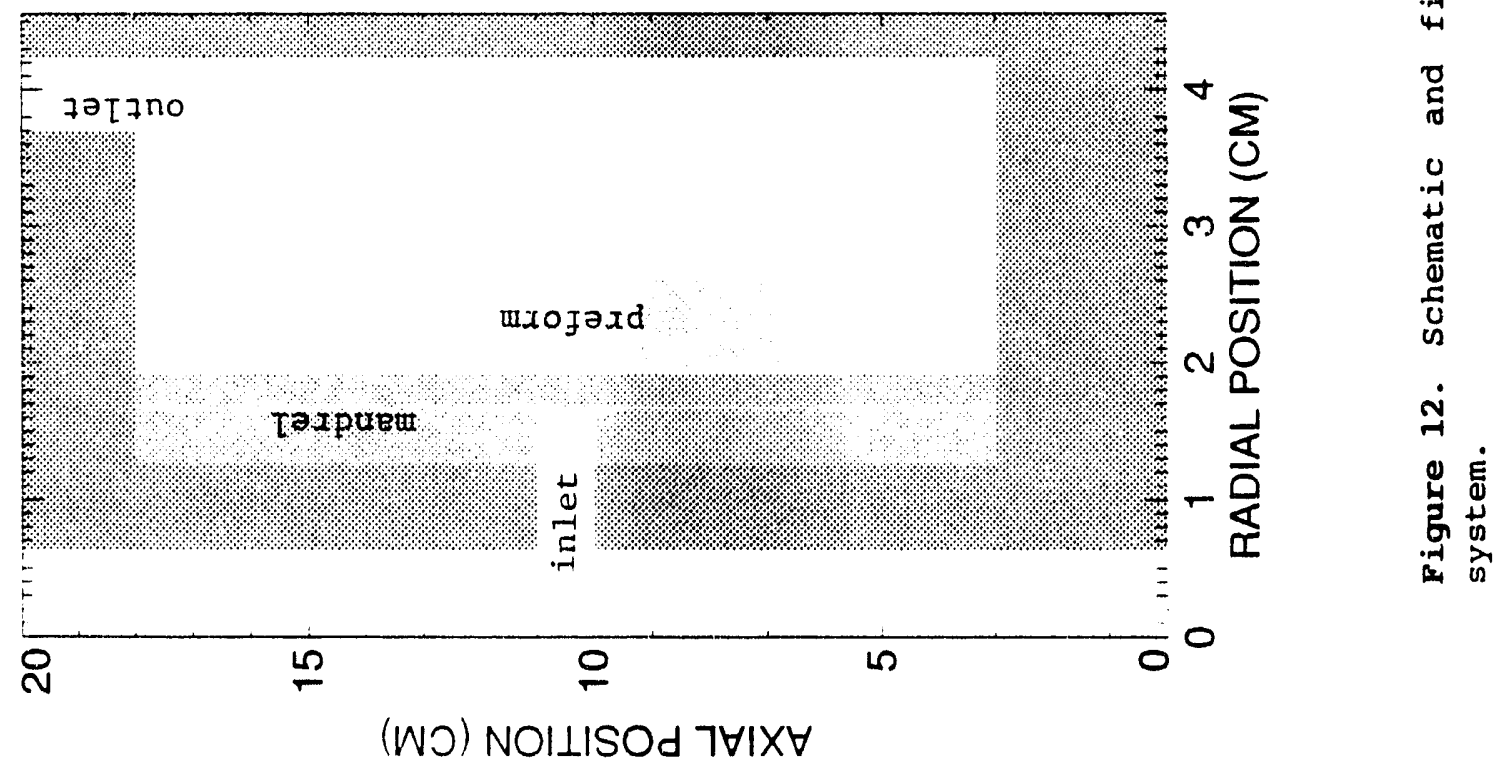


苛

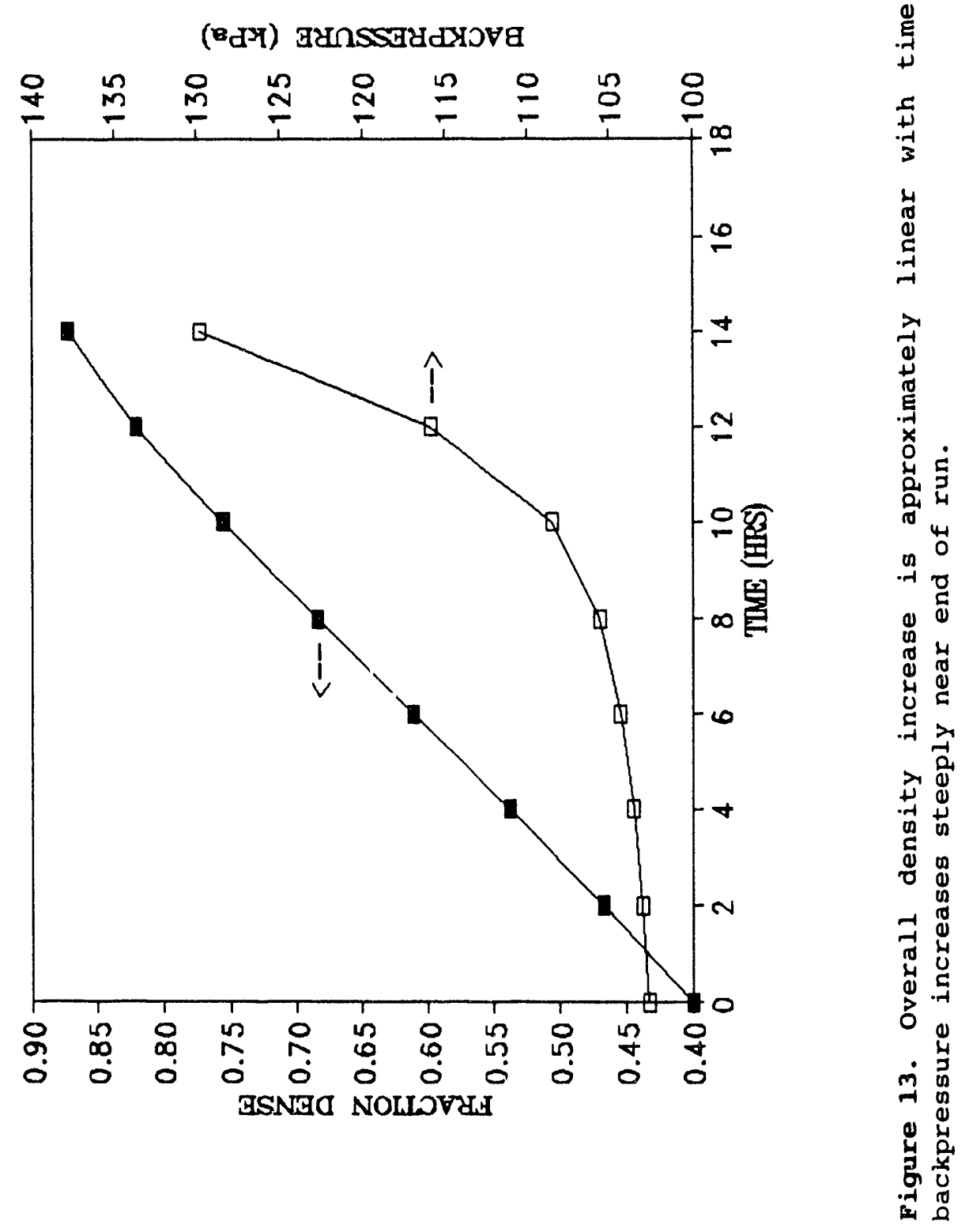



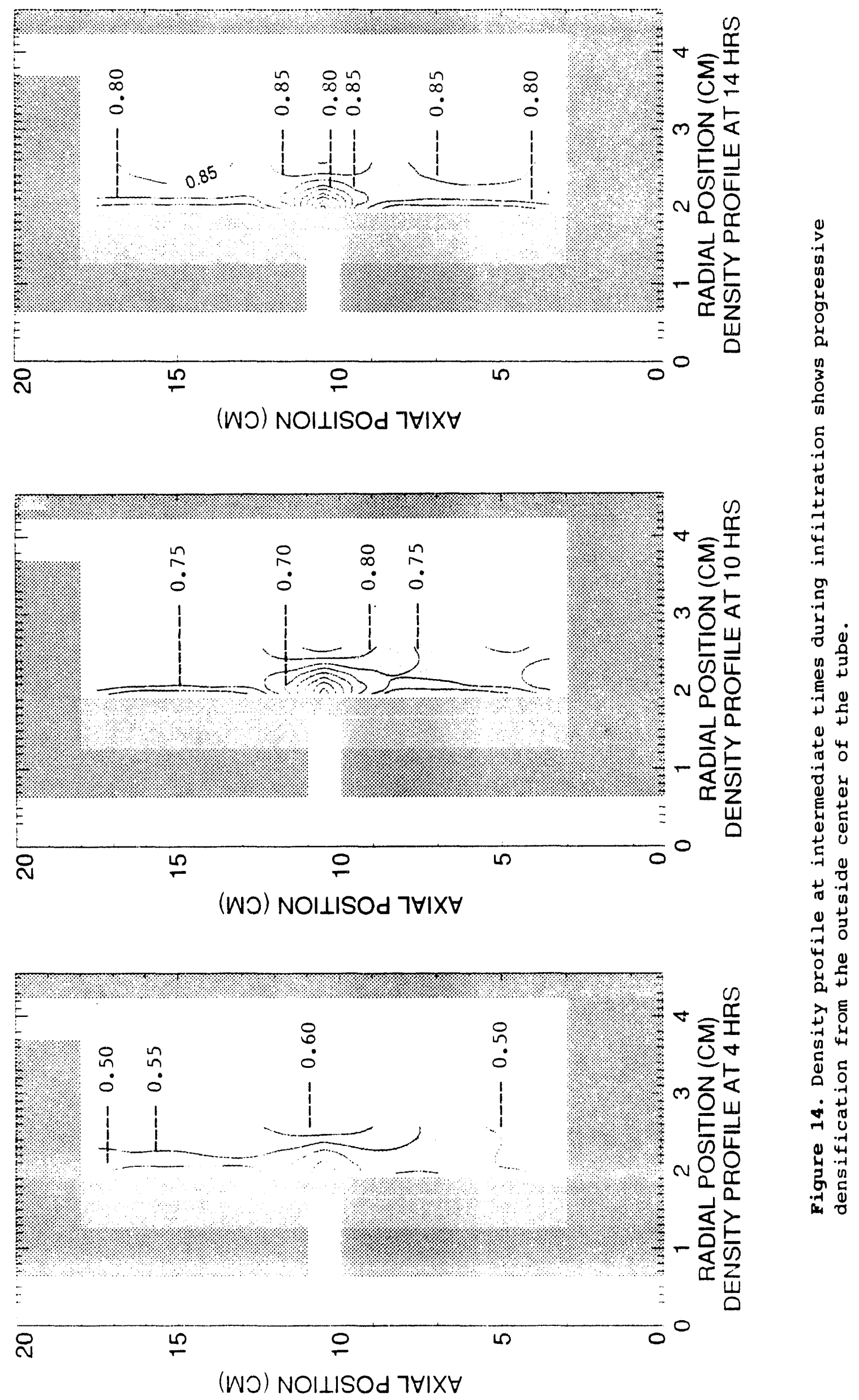


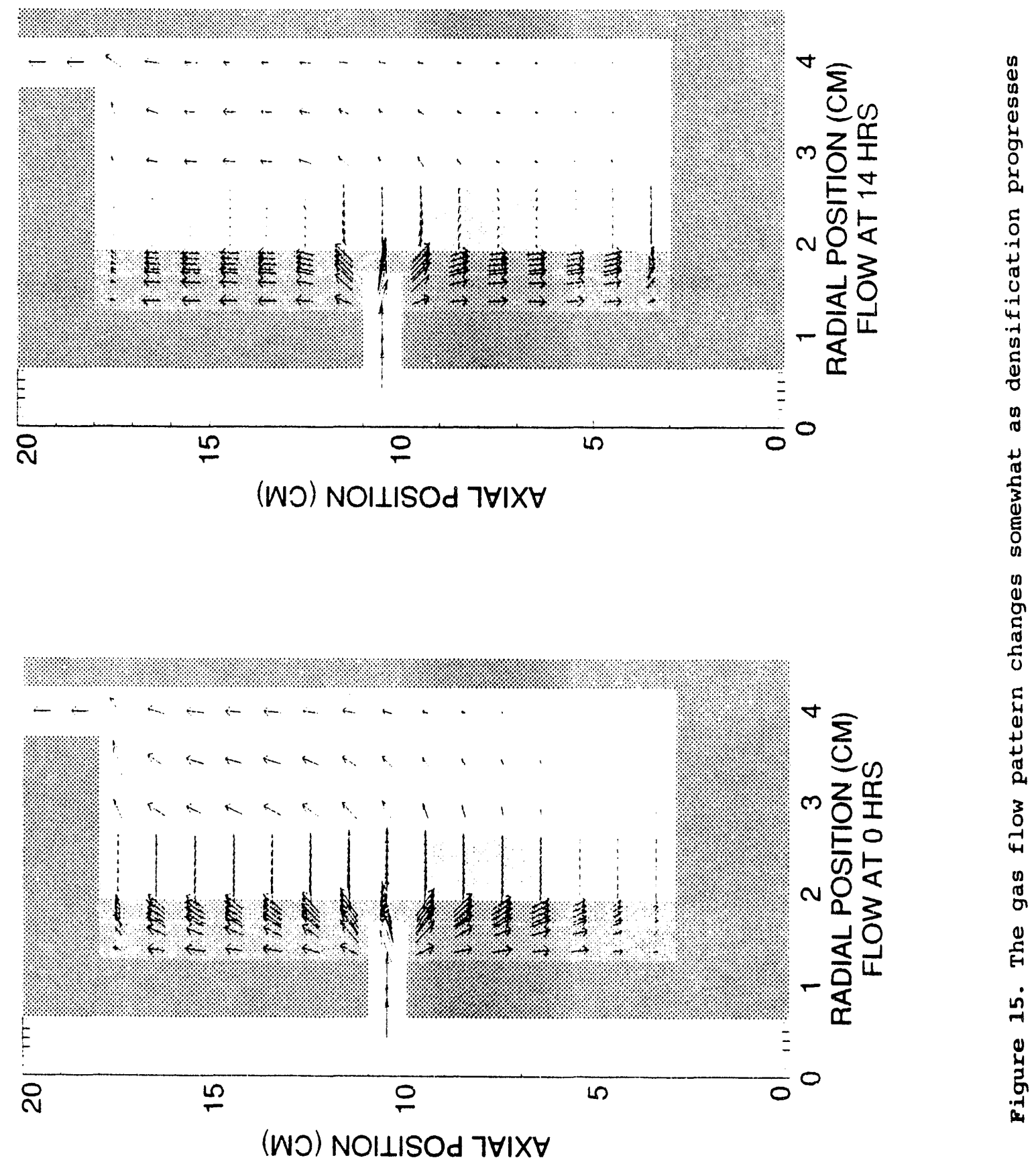



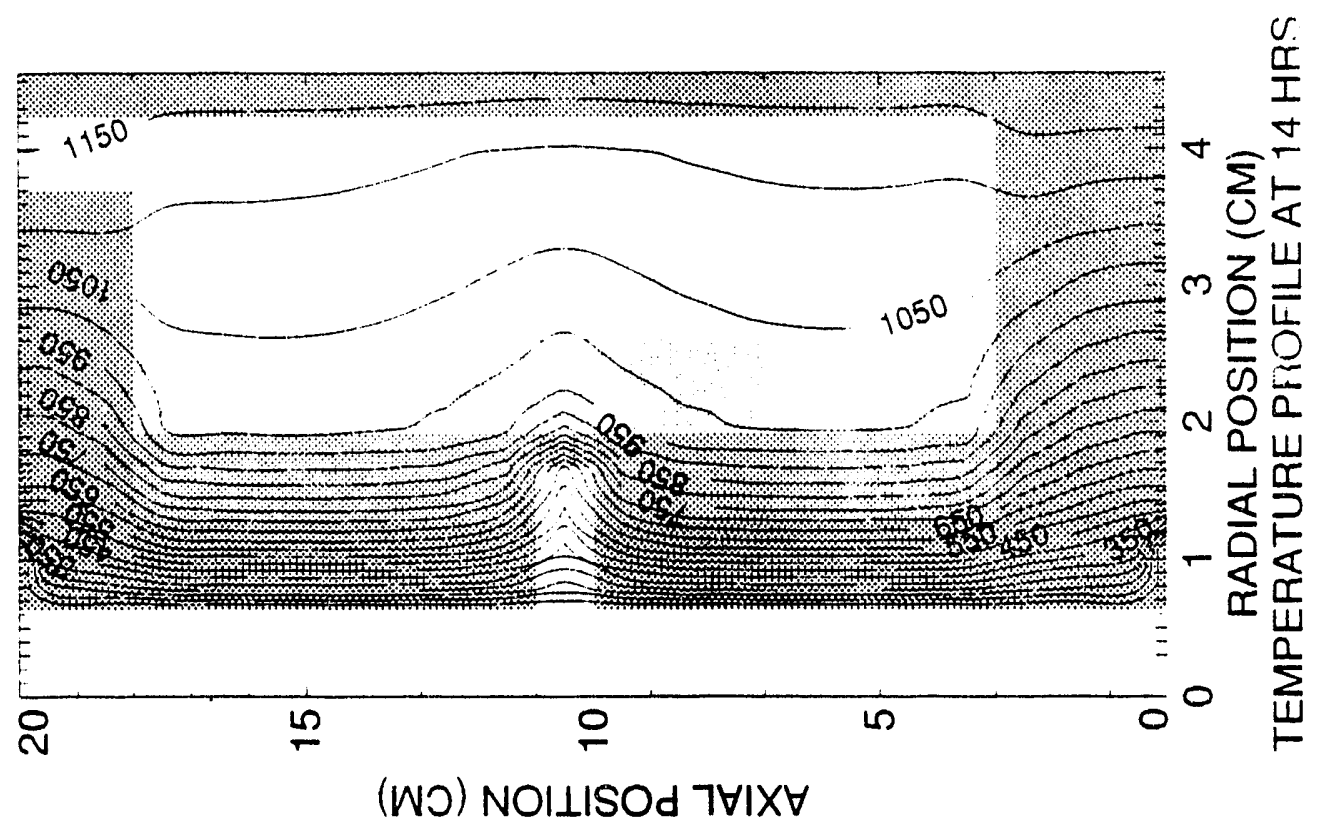

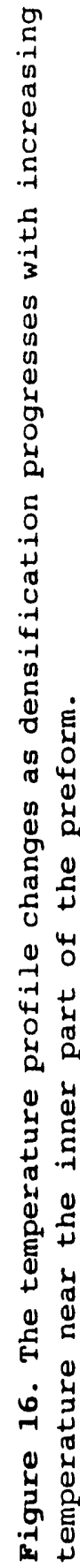

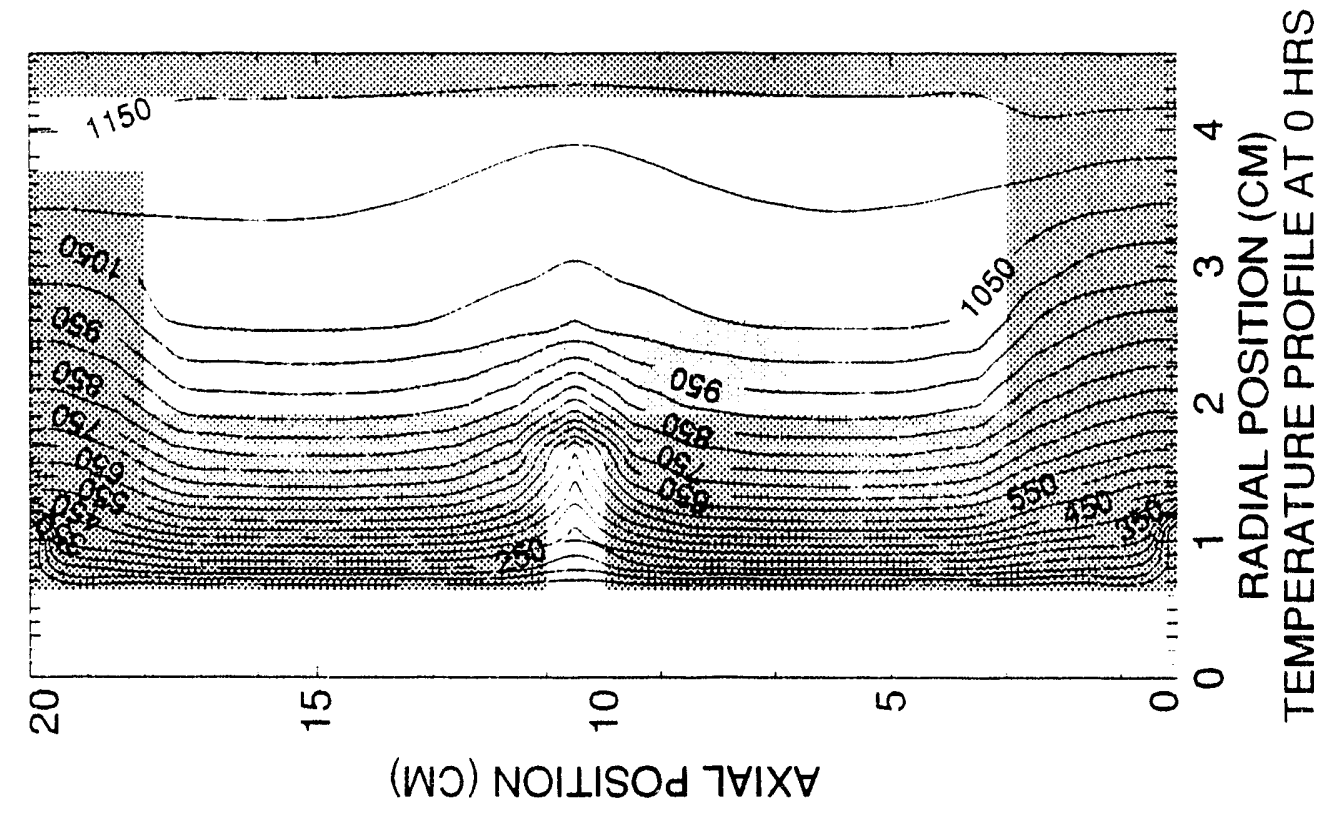




\section{SUMMARY AND CONCLUSIONS}

A finite volume model for forced flow/thermal gradient CVI has been implemented. We believe that this model includes all physical phenomena that are significant to the FCVI process. The model can be used to select optimum infiltration conditions for preforms of various geometries and reduce the number of experimental runs needed for process development. Future applications of the model will focus on tube shaped components and on oxide matrix composites. 
REFERENCES

1. T. M. Besmann, B. W. Sheldon, R. A. Lowden and D. P. Stinton, Science 253, 1104 (1991).

2. T. L. Starr, "Modeling of Chemical Vapor Infiltration," Oak Ridge National Laboratory Report ORNL/Sub/85-55901/01 (February 1989).

3. S. V. Patankar, Numerical Heat Transfer and Fluid Flow (Hemisphere Publishing Corp., New York, 1980.

4. R. A. Lowden, A. J. Caputo, D. P. Stinton, T. M. Besmann and M. D. Morris, "Effect of Infiltration Conditions on the Properties of SiC/Nicalon Composites," ORNL/TM-10403, Oak Ridge National Laboratory, Oak Ridge, TN (May 1987).

5. K. Brennfleck, E. Fitzer, B. Schoch and M. Dietrich, in Proc. Ninth Int. Conf. on Chemical Vapor Deposition, Electrochemical Society, Pennington, NJ, pp. $649-662(1984)$.

6. T. L. Starr, "Modeling of Forced Flow/Thermal Gradient CVI," in Whisker-and Fiber-Toughened Ceramics, edited by R.A. Bradley, D.E. Clark, D.C. Larsen and J.o. Stiegler (ASM International, Metals Parks, OH 1988) pp. 243-251.

7. T. M. Besmann, B. W. Sheldon, T. S. Moss and M. D. Kaster, J. Amer. Ceram. Soc., in press.

8. H. Tawil, I. D. Bentsen, S. Baskaran, D. P. H. Hasselman, J. Mat. Sci. $\underline{20}, 3201-3212(1985)$.

9. CRC Handbook of Chemistry and Physics, edited by Robert C. Weast, Melvin J. Astel and William H. Beyer, 68th Edition, CRC Press, Boca Raton, Florida, 1987-88

10. C. N. Satterfield and T. K. Sherwood, The Role of Diffusion in Catalysis, Addison-Wesley Publishing Company, Reading, Massachusetts, 1963.

11. T. I. Starr and D. P. Stinton, in proceedings of the American Society for Composites, Fifth Technical Conference, edited by. L. T. Drzal, (Technomic Publishing Company, Lancaster, Pennsylvania, 1990) pp. 765-773.

12. T. M. Besmann, T. S. Moss and J. C. Mclaughlin, presented at the 16 th Annual Conference on Composites and Advanced Ceramics, Cocoa Beach, Florida, 1992 (unpublished). 


\section{DISTRIBUTION}

A.P. (GREEN REFRAC'TORIES COMPANY

Green [3lvd.

Mexict), $M() 0.5265$

J. L. Hill

AIR PRODUCTS AND CHEMICALS

P.O. Box 538

Allentown, PA 18105

S. W. Dean

S. C. Weiner

\section{ALLISON GAS TURBINE DIVISION}

P.O. BOX +20

Indianapolis, IN $+6206-0420$

P. Khandelwal (Speed Code W-5)

R. A. Wenglarz (Speed Code W-16)

AMA RESEARCH \& DEVELOPMENT CENTER 5950 McIntyre Street

Golden, CO 80403

T. B. $\operatorname{cox}$

\author{
ARGONNE NATIONAL LABORATORY \\ $9700 \mathrm{~S}$. Cass Avenue \\ Argonne, IL 60439 \\ W. A. Ellingson \\ J. P. Singh
}

ARGONNE NATIONAL LABORATORY-WEST

P.O. Box 2528

Idaho Falls, ID 83403-2528

S. P. Henslee

\author{
ARMY MATERIALS TECHNOLOGY \\ LABORATORY SLCMT-MCC. \\ Watertown, MA 02172-0001 \\ D. R. Messier
}

AVCO RESEARCH LABORATORY

2385 Revere Beach Parkway

Everell, MA 02149

R. J. Pollina

BABCOCK \& WILCOX

1562 Beeson St.

Alliance, $\mathrm{OH}+4601$

T. I. Johnson

BABCOCK \& WILCOX

Domestic Fossil Operations

20) South Van Buren Avenue

Barberton, OH 44023

M. Gold
BABCOCK \& WILCOX

Lynchburg Research Center

P. O. BOX 11165

Lynchburg, VA 24506

H. M. Mocller

BRITISH COAL CORPORATION

Coal Research Establishment

Stoke Orchard, Cheltenham

Glochester, England GL52 4RZ

M. Arnold

C. Bower

A. Twigg

BRITISH GAS CORPORATION

Westfield Development Center

Cardenden, Fife

Scotland KY5OHP

J. E. Scolt

BROOKHAVEN NATIONAL LABORATORY

Department of Applied Science

Upton, Long Island, NY 11973

T. E. O'Hare

CANADA CENTER FOR MINERAL \& ENERGY TECHNOLOGY

568 Booth Street

Ottawa, Ontario

Canada KIA OG!

R. Winston Revic

Mahi Sahoo

DOW CORNING CORPORATION

3901 S. Saginaw Road

Midland, MI 48686-0995

H. Atwell

EC TECHNOLOGIES

3614 Highpoint Drive

San Antonio, TX 78217

D. J. Kenton

ELECTRIC POWER RESEARCH INSTITUTE

P.O. Box 10412

3412 Hillview Avenue

Palo Alto, CA 94303

W. T. Bakker

J. Stringer EUROPEAN COMMUNITIES JOINT RESEARCH
CENTRE

Petten Establishment

P.O. BOX 2

1755 ZG Pellen

The Netherlands

M. Van de Voorde 
GA TECHNOLOGIES. INC.

P.O. BOX 85608

San Diego, CA 92138

T. D. Gulden

GEORGIA INSTITUTE OF TECHNOLOGY

Georgia Tech Research Institute

Allanta, GA 30332

T. L. Starr

IDAHO NATIONAL ENGINEERING

LABORATORY

P. O. BOX 1625

ldaho Falls, ID $83+15$

D. W. Keefer

B. H. Rabin

KENNAMETAL, INC.

Philip McKenna Laboratory

1011 Old Salem Road

P. O. Box 639

Greensburg, PA 15601

B. North

\section{LAVA CRUCIBLE-REFRACTORIES CO.}

P.O. Box 278

Zelienople, PA 16063

T. Mulholland

L.AWRENCE LIVERMORE LABORATORY

P.O. BOX 808, L. 325

Livermore, C.A 94550

W. A. Steele

LOS ALAMOS NATIONAL LABORATORY

P.O. Box 1663

Los Alamos, NM 8754.5

J. D. Katz

MASSACHUSETTS INSTITUTE OF TECHNOLOGY

Department of Civil Engineering

Room I-280, 77 Massachusetts Avenue

Cambridge, MA 02139

O. Buyukozlurk

NATIONAL INSTITUTE OF STANDARDS AND TECHNOLOGY

Materials Building

(ialthersburg, MD 20899)

L.. K. Ives

A. Pechenik

NATIONAL. MATERIALS ADVISORY BOARD

Nitlonal Rescirch Cisuncil

2101 Constatutuon Avenue

Washington, DC. 2()$+18$

K. M. Zwilsky
NEW ENERGY AND INDUSTRIAL TECHNOLOGY DEVELOPMENT

Sunshine 60 Bldg.

P.O. Box 1151

1-1 Higashi-Ikcbukuro 3-Chrome

Toshima-Ku, Tokyo, 170

Japan

H. Narita

S. Ueda

THE NORTON COMPANY

High Performance Ceranics Division

Goddard Road

Northborough, MA 01532-1545

N. Corbin

OAK RIDGE NATIONAL LABORATORY

P.O. Box 2008

Oak Ridge, TN 37831

P. T. Carlson

N. C. Cole

R. R. Judkins

R. A. Lawson (8 copies)

D. P. Stinton

OFFICE OF NAVAL RESEARCH

Code $431,800 \mathrm{~N}$. Quincy Street

Arlington, VA 22217

S. G. Fishman

RESEARCH TRIANGLE INSTITUTE

P. O. Box 12194

Research Triangle Park, NC 27709

T. W. Sigmon

SHELL DEVELOPMENT COMPANY

P.O. Box 1380

Houston, TX 77251-1380

L. W. R. Dicks

TENNESSEE VALLEY AUTHORITY

Energy Demonstration \& Technology MR2N58A

Chattanooga, TN 37402-2801

C. M. Huang

\section{M COMPANY}

Ceramic Materials Department

201-2C-12 3M Center,

St. Paul, MN 55144

L. R. White

THE JOHNS HOPKINS UNIVERSITY Materials Science \& Engineering

Marjland Hall

Ballimore, MD $21218^{\circ}$

R. E. Green, Jr. 
THE MATERIALS PROPERTIES COUNCII, INC. United Engmecring Center 345 E. Forty-Seventh Street

New York, NY 10017

M. Prager

THE TORRINGTON COMPANY

Advanced Technology Center

50 Field St.

Torringion, CT 06790

W. J. Chmura

UNION CARBIDE CORPORATION

Linde Division

P.O. Box t4

175 Easi Park Drive

Tonawanda, NY 1+151-0044

Harry Cheung

UNITED TECHNOLOGIES RESEARCH CENTER MS 24, Silver Lane

East Hartford, CT 06108

K. M. Prewo

UNIVERSITY OF WASHINGTON

Department of Materials Science and Engineering

10! Wilson, FB-10

Seantle, WA 981 \%

T. G. Stoebe

VIRGINIA POLYTECHNIC INSTITUTE \& STATE UNIVERSITY

Department of Materials Engineering

Blackburg, VA 24601

J. J. Brown, Jr.

K. L. Reifsnider

WESTERN RESEARCH INSTITUTE

365 N. 9th Street

P.O. Box 3395

University Station

Laramie, WY 8207!

V. K. Selhi

WESTINGHOUSE EI.ECTRIC CORPORATION

Research and Development Center

1310 Beulah Road

Pittsburgh, PA 1.5235

$S$. C. Singhal

WESIINGHOUSE HANFORD COMPANY

P.O. Box 1970

W/A.65

Richland, Wa M9.52

R. N. Johnson
DOE

IDAHO OPERATIONS OFFICE

P. O. Box 1625

ldaho Falls, ID $83+15$

R. B. Loop

DOE

DOE OAK RIDGE FIELD OFFICE

P.O.Box 2001

Oak Ridge, TN 37831

Assistant Manager for Energy Research and Development

DOE

DOE OAK RIDGE HIELD OFFICE

P. O. Box 2008

Building $4500 \mathrm{~N}$, MS 6269

Oak Ridge, TN 37831

E. E. Hoffman

DOE

OFFICE OF BASIC ENERGY SCIENCES

Materials Sciences Division

ER-131 GTN

Washington, DC 20545

J. B. Darby

DOE

OFFICE OF CONSERVATION AND RENEWABLE ENERGY

CE-12 Forrestal Building

Washington, DC 20545

J. J. Eberhardt

DOE

OFFICE OF FOSSIL ENERGY

Washington, DC 20545

J. P. Carr (FE-14) GTN

DOE

OFFICE OF VEHICLE AND ENERGY R\&D

CE-151 Forrestal Building

Washington, DC 20585

R. B. Schulz 
DOE

MORGANTOWN ENERGY TECHNOIOGY

(IINTIER

P.(). Bus sos

Morgantown, WV 2050)5

R. A. Bajura

R. C. Bedick

D. C. Cicero

F. W. Crouse, Jr.

N. T. Holcombe

W. J. Huber

M. J. Mayrield

J. E. Notestein

J. S. Wilson

DOF:

PITISBURGH ENERGY TECHNOLOGY CENTER

P.O. Box 10940

Pittsburgh, PA 15236
A. H. Baldwin
G. V. McGurl
R. Santore
T. M. Torkos 

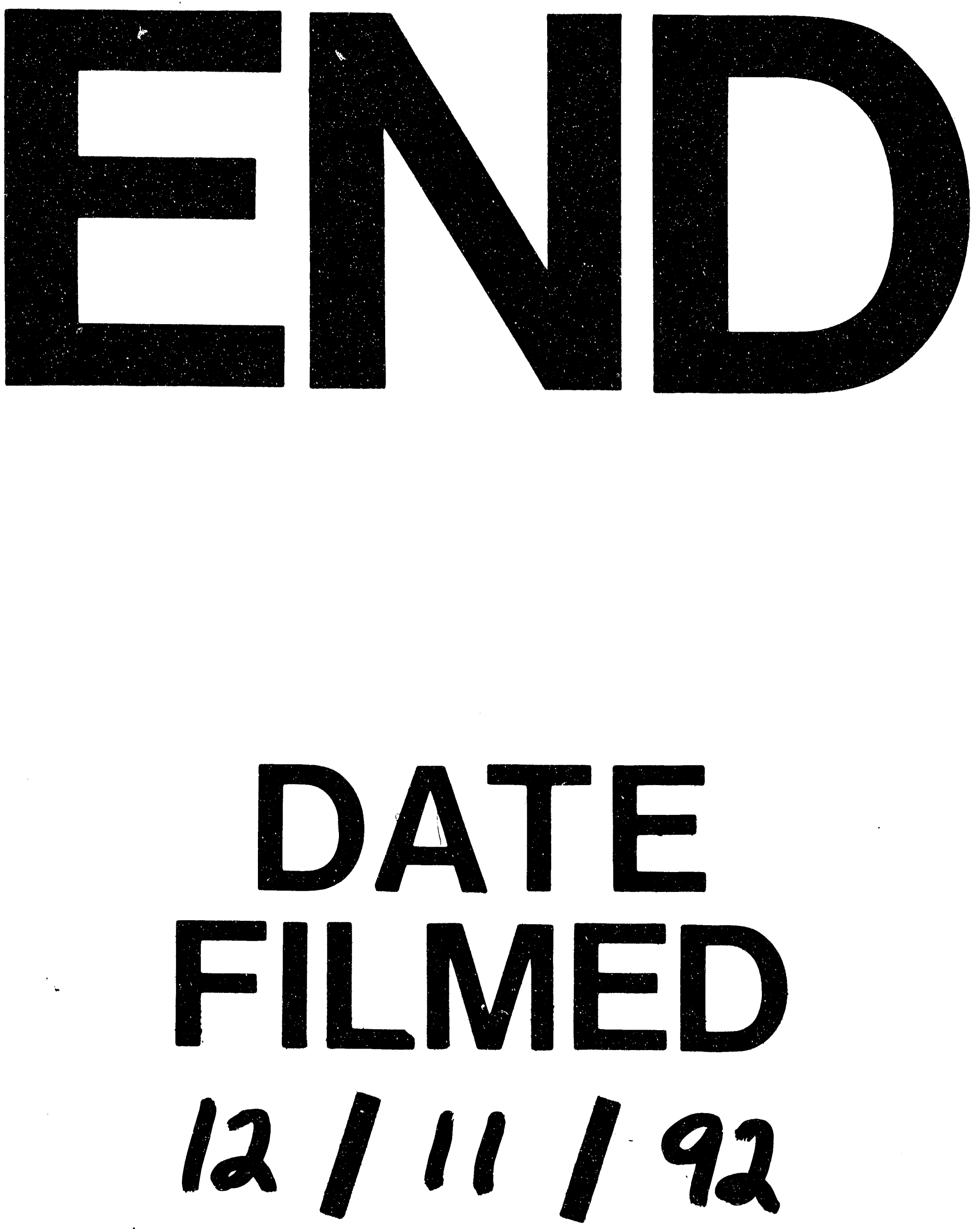

1 
